\title{
ЛАТИНОАМЕРИКАНСКИЙ ПОДХОД К РЕШЕНИЮ МЕЖДУНАРОДНЫХ ПРОБЛЕМ
}

\begin{abstract}
Аннотация: В основу исследования легли проблемы позиционирования Латинской Америки на мировой арене. Анализируются вопросы мирового порядка и применения hard power, поскольку именно по ним возникают идеологические расколы между участниками мировой политики. Основное проблемное поле исследования охватывает вопросы мирового порядка, архитектуры системы глобального управления, применения силь в решении международных проблем. Рассматриваются позиции различных латиноамериканских стран по таким вопросам как: применение санкций, признание независимости государств, создание международных организаций и т.п. В основе исследования лежит факторный анализ, с помощью которого выделялись ключевые проблемы международных отнотений. Через сравнительный подход устанавливались закономерности позичионирования государств Латинской Америки на международной арене. Особым вкладом автора в исследование является выявление общности позиции стран региона относительно устройства мира (все государства выступают за многополярность). Позищии стран совпадают в пределах объединяющей структуры - интеграчионного образования МЕРКОСУР, АЛБА, Тихоокеанский альянс. Коррелячия латиноамериканских подходов с российским крайне высокая, что доказывает перспективность развития политического диалога России с государствами Латинской Америки на различных международных площадках (Генеральная Ассамблея ООН, Совет Безопасности ООН, БРИКС и др).
\end{abstract}

Ключевые слова: Латинская Америка, мировой порядок, многополярность, отвественность по защите, гуманитарные интервенции, санкиии, международное право, суверенитет, невмемательство, терроризм.

Abstract: This article is dedicated to the research of the issues of positioning of Latin America in the global arena. The author analyzes issues of world order and use of "hard power", as these are namely the causes for ideological disagreements between the members of world politics. The main problematic field of the research addresses the questions of world order, architecture of the system of global governance, and use of force in resolution of international conflicts. The article sheds light on the positions of various Latin American countries on questions such as: implementation of sanctions, recognition of sovereignty of states, creation of international organizations, etc. The author reveals certain common positions of the countries of the region regarding the world structure (all countries stand for multipolarity). Positions of the countries coincide within the unifying structure - integrational bloc Mercosur, ALBA, and Pacific Alliance. The correlation of Latin American approaches with Russian is rather high, which is promising for the development of political dialogue between Russian and the countries of Latin America on various international platforms (General Assembly of the United Nations, UN Security Council, BRICS, and others).

Keywords: International law, sanctions, humanitarian interventions, duty to protect, multipolaity, world order, Latin America, sovereignty, non-interference, terrorism.

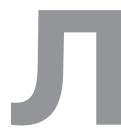
атиноамериканский регион начинает играть все более значимую роль в мировой политике. Текущее положение, которое регион занимает в системе международных отношений, характеризуется следующими особенностями:

- благодаря интеграционным процессам в системе международных отношений занимают место не только отдельные страны Латинской Америки, но и региональные объединения;
- регион только выходит на международную арену после долгого американского влияния. Внешнеполитические постулаты, с которыми выступают страны региона, в основном направлены на противодействие гегемонистской политике США, расширение связей с другими крупнейшими полюсами влияния;

- периферийное положение региона, сформировавшийся образ в мировой политике как стран третьего мира, в последнее время преодолевается активной по- 
DOI: $10.7256 / 1811-9018.2015 .6 .14698$

При цитировании этой статьи сноска на доі обязательна

\section{Право и политика $6(186) \cdot 2015$}

литикой государств на международных площадках по ключевым вопросам современного порядка, мира и безопасности. Прежняя ориентированность государств на внутри региональные и локальные проблемы меняется на более активную позицию, хотя в целом регион остается своеобразным резервом наращивания влияния, усиливая или ослабляя позиции полюса мировой политики[1];

- в регионе расположены «пороговые государства», которые в силу своего высокого потенциала могут войти в клуб глобального регулирования. Это в первую очередь Бразилия (член крупнейшего объединения БРИКС, претендент на постоянное членство в Совете Безопасности ООН), Мексика и Аргентина[2]. Однако это возможно лишь в случае экономического подъема, научно-технического прогресса и политической воли у руководства стран. При вхождении пороговых государств в круг глобального управления стоит ожидать изменения мирового порядка вследствие демократизации международных отношений, перераспределения ответственности в мировых делах;

- промежуточное положение Латиноамериканского региона в мировой иерархии означает, что подходы, стратегические интересы стран региона совпадают с развивающимися странами и находятся в противопоставлении западному миру. В частности, усиливая партнерские отношение, в том числе в рамках организации 77, регион способен стать катализатором пересмотра сложившегося мирового порядка, хотя ряд государств продолжает ориентироваться не на субрегиональных лидеров, а на глобальных игроков или прежних метрополий (страны Карибского бассейна сориентированы на США и Великобританию, Суринам - на Нидерланды, Гаити - на Францию);

- хотя регион тяготеет к Европе (единые католические ценности, этнокультурная и языковая общность), доминирующим становится потребность в факторах, которые могут обеспечить определенную свободу действий в международных отношениях. Ранее таким фактором - противовесом гегемонии с Севера - выступал СССР. Страны региона, которые заинтересованы в экономическом сотрудничестве с США, в то же время ориентированы на альтернативные варианты международного партнерства. Россия при дальнейшем промедлении может упустить исторический момент, когда латиноамериканские государства «выбирают» альтернативный гегемонии Вашингтона полюс притяжения. Уже на очереди стоят такие крупнейшие мировые игроки, как ЕС, КНР, Иран и Индия. Поиск альтернативных партнеров подтверждается сменой ориентиров во внешней политике: на смену концепции открытого регионализма в 2005 году приходит постлиберальный регионализм, который во внешней политике также ориентирован на привлечение новых партнеров, как и открытый, но акцент партнерства расставлен не на экономике, а на вопросах социального равенства, мира, безопасности.

Латиноамериканские государства не ограничивают сферу интересов региональными проблемами, но и активно вовлечены в международные процессы через участие в мировых институтах и организациях. Позиции государств региона во многом совпадают как между собой, так и с российской.

\section{Мировой порядок}

Регион единогласно выступает за многосторонние начала в мировой политике. Так, в 2004 году на саммите «Группы Рио» государства подтвердили многосторонний подход к решению глобальных проблем. Идея многополярности стала доминирующей во всех странах региона и задокументирована в коллективных документах латиноамериканской дипломатии, двусторонних договорах и соглашениях с Россией, Индией, Китаем, в выступлениях государственных и общественных деятелей, в документах Ибероамериканских саммитов [21]. Так, в частности, заключительные декларации Ибероамериканских саммитов содержат следующие подходы латиноамериканских стран к многополюсному устройству мира: признание принципов невмешательства, самоопределения и государственного суверенитета при уважении демократических норм и прав человека, неприятие гегемонии и попыток утверждения экстерриториальности внутреннего законодательства (Закон Хелмса-Бартона), «гуманитарных интервенций» без санкции СБ ООН, экономического диктата, усиления торгового протекционизма под предлогом борьбы с экологическим или социальным демпингом [3]. В декларации Сан-Хосе (14 Ибероамериканский саммит, 2004 г.) зафиксировано: «только многосторонний подход к решению международных проблем и вызовов безопасности...способен гарантировать в дальнейшем мирное и демократическое развитие с учетом социальных нужд населения Земли». Идея многополярного мира также закреплена в Декларации о принципах взаимоотношений между РФ и Кубой (1996 г.), Декларации о принципах взаимоотношений между Россией и Бразилией, устремленных в XXI век. В ряде деклараций о принципах с другими странами содержатся положения о справедливом миропорядке, верховенстве международного права, ведущей роли ООН. 
Подтверждая ведущую роль ООН, латиноамериканские государства поддерживают идею расширения постоянного членства Совете Безопасности с представительством всех регионов в структуре. Так, потенциальными кандидатами выступают Бразилия и Мексика. Российский президент В.В.Путин в ходе визита в Бразилию в 2004 году выразил поддержку Бразилии по вопросу вступления в состав постоянных членов Совета Безопасности. Экс-президент Чили Пиньера выступил за глубокое реформирование Совета Безопасности «необходимо отказаться от практики наложения вето, которая принадлежит уже несуществующему миру, и заменить ее практикой специальных совещаний»[4].

Опорой многополюсного миропорядка страны Латинской Америки считают международное право, с помощью которого регулируются глобальные проблемы, гарантом международного порядка - OOH, региональные системы безопасности. Традиционное отрицание разрешения споров силовыми методами восходит к практике региона: отсутствие вооруженных конфликтов, единичное число войн (самая крупная Чакская война 1932 - 1935 гг.), сравнительно низкий масштаб конфликтов, которые можно классифицировать как приграничные конфликты [5].

Терроризм. Латиноамериканские страны поддержали создание антитеррористической коалиции, но обозначили ряд оговорок. Так, Бразилия заявила, что в борьбе с международным терроризмом нельзя ограничиваться силовыми методами, необходимо обратить внимание на объективные причины явления, в первую очередь - разрыв между уровнями экономического развития передовых и отсталых стран. Осудила инициативу вторжения Венесуэла. Кубинский лидер, в частности, указал на то, что терроризм нельзя связывать с государствами-изгоями и осью зла, недопустимо использовать терроризм в качестве политического предлога. Страны, так же как и Россия, поддержали действия антитеррористической коалиции в Афганистане, но многие государства воздержались от безоговорочного одобрения позиции США и Великобритании по Ираку (дискуссии вокруг резолюции СБ ООН №1441) [6]. Мексика и Чили как непостоянные члена СБ ООН отказались поддерживать эту резолюцию, которая предусматривала легализацию военного вторжения в Ирак, без проверенных доказательств обладания Ираком оружием массового уничтожения. Мексика также инициировала создание группы шести (Ангола, Гвинея, Камерун, Мексика, Пакистан, Чили), выступавшей едино за недопустимость урегулирования проблемы военными методами. Активная позиция Мексики в данном вопросе связана с традиционным мексиканским пацифизмом и принципом невмешательства во внутренние дела [7].

Поддержали интервенцию и направили туда воинские контингенты такие латиноамериканские страны, как Никарагуа (не правительство Д.Ортеги), Сальвадор, Гондурас, Доминиканская республика.

Уникальность латиноамериканского подхода к борьбе с терроризмом в отличие от западного, который разжигает расовую рознь многочисленными карикатурами на пророка Мухаммеда и провокациями, состоит в том, что в основу борьбы «должна быть положена проблематика человека: его религии, культуры и условий существования». В Лимской декларации содержится призыв к диалогу цивилизаций и уважению к культурным, расовым и этническим различиям людей в качестве средства, способствующего воспитанию на Земле «культуры мира»[8]. Еще до событий 11 сентября 2001 года латиноамериканские страны прогнозировали, что «бум исламского фундаментализма» может возникнуть как реакция на насильственное привитие всем регионам стандартов потребления и культуры одной-единственной цивилизации - западной.

Таким образом, как и в российской практике, основной упор при противодействии терроризму страны делают на его профилактику, а не на силовое противодействие, практикуемое Западом (Европа и США).

\section{Косово}

Страны региона в большинстве своем не признали независимости Косово и настаивали на вынесении данного вопроса в международный суд $\mathrm{OOH}$. В 2008 году Генеральная Ассамблея ООН обратилась в Международный суд с целью получения заключения по вопросу «Соответствует ли одностороннее провозглашение независимости временными институтами самоуправления Косово нормам международного права?». Данную резолюцию поддержали Аргентина, Боливия, Бразилия, Гондурас, Гватемала, Доминиканская республика, Коста-Рика, Куба, Мексика, Никарагуа, Панама, Парагвай, Сальвадор, Суринам, Чили, Уругвай. Воздержались Колумбия и Перу. Из крупнейших стран региона признали независимость Перу и Колумбия, отказались - члены МЕРКОСУР и АЛБА. Аргентина обосновала свои взгляды тем, что это затруднит урегулирование проблемы Фолклендских островов. Боливия видела в этом опасный прецедент для собственной территориальной целостности (автономия восточных районов). Бразилия настаивала на консультации в 
DOI: $10.7256 / 1811-9018.2015 .6 .14698$

При цитировании этой статьи сноска на доі обязательна

\section{Право и политика $6(186) \cdot 2015$}

рамках СБ ООН. Венесуэлы утверждала, что этот прецедент способен повлечь войны в мире.

\section{Вмешательство во внутренние дела государства}

Латиноамериканские страны осуждают гуманитарные интервенции и подмену международного права силой сверхдержавы, игнорирование политических механизмов урегулирования вооруженных конфликтов. Отношение стран к гуманитарным интервенциям сводится к формуле, предложенной известным уругвайским юристом-международником Э. Хименес де Аречага: «в качестве примера оправданного применения силы чаще всего приводят вмешательство по соображениям гуманитарного характера. По нашему мнению, соображения гуманитарного характера не превращают интервенцию в правомерный акт» [9]. Так, военная акция НАТО в Югославии вызвала негативную реакцию, государства Латинской Америки в большинстве выступили против решения вопроса в обход $\mathrm{OOH}$ и Совета Безопасности. Группа Рио, в состав которой входят все латиноамериканские страны (кроме Кубы), выступила в 1999 году с совместным заявлением, в котором содержалось «сожаление», что НАТО применило силу на Балканах в обход п.1.ст.54 Устава ООН, призвала все стороны решить проблему посредством переговоров [19].

Осудив силовое вмешательство, регион поддержал инициативу по осуждению гуманитарных интервенции и разработку новой концепции реагирования на нарушение прав человека, получившей название «Ответственность по защите» (R2P). Она была выработана в 2001 году Международной комиссией по вопросам вмешательства и государственного суверенитета (МКСГС). Формула, предложенная комиссией, гласила, что суверенитет не только предоставляет какому-либо государству право «контролировать» свои внутренние дела, но также налагает непосредственную обязанность по защите людей, проживающих в пределах границ этого государства [20]. В докладе предлагалось, что в случае неспособности государства защитить свой народ, будь то из-за отсутствия возможности или желания это делать, ответственность по защите людей передается международному сообществу. Неудачный опыт реализации концепции в Ливии инициировал политическую активность Бразилии и Китая, которые предложили дополняющие концепции. Бразильская концепция указывает, что применение силы должно быть крайним средством, которому должен предшествовать всесторонний анализ возможных последствий военных действий в каждом конкретном случае, поскольку даже в том случае, когда это оправдано, военные действия приводят к высоким человеческим и материальным потерям. Бразилия отрицает возможность применения концепции как предлог смены режима, полагая, что такой подход лишает концепцию реальной силы в мировом сообществе [10]. Бразильский проект мог бы внести весомый вклад в развитие концепции и минимизировать возможные риски при реализации силового компонента. Однако критика со стороны западных государств, их противодействие затормозили процесс развития концепции, в то же время Россия выступила за поддержку бразильского проекта. Реакции США и Европы на предложения Бразилии заключается в сокрытой уверенности в том, что процесс эволюции нормы должен идти на Западе. Зарождение нормы происходило на Западе, затем по инициативе западных держав она кодифицировалась, незападные страны в подобной модели могли только принять или отклонить норму. И только в случае необходимости модификации нормы незападные державы могли участвовать в нормотворчестве на уровне неправительственных организаций. В связи с этим, появление предложений от Бразилии бросило вызов западным государствам, которые тем самым стали терять монополию на установление норм мирового порядка. Но «ответственность по защите» это не строго установленный закон, а норма, которая нуждается в доработке и развитии. Регион остается самым представительным на площадке обсуждения механизмов совершенствования концепции в силу высокого интереса государств к проблеме, которая также на протяжении всей истории затрагивала их неоднократно (интервенции США).

\section{Ливийская интервенция}

Бразилия не поддержала как непостоянный член резолюцию Совет Безопасност 1973 по установлению беспилотной зоны (в рамках концепции «Ответственность по защите»). Она выразила обеспокоенность, что беспилотная зона может быть использована как предлог для прямой интервенции с целью свержения М.Каддафи. Члены АЛБА раскритиковали интервенцию НАТО в Ливию, назвав это вооруженным вторжением с целью захвата ливийской нефти. Против выступил Эквадор, предложивший сформировать в рамках УНАСУР единую позицию по невмешательству в регион Ближнего Востока, который вправе самостоятельно решать проблемы без интервенций [11]. Боливия настаивала на немедленном прекращении агрессии и начале 
переговорного процесса. Аргентина раскритиковала интервенцию и указала на то, что не все переговорные инструменты были исчерпаны.

Поддержали венные действия Колумбия, Чили, президент которой С.Пиньера указал на то, что лидер страны, который бомбит свое население, не может управлять страной. Перу, как и другие члены Тихоокеанского союза, выступил за интервенцию.

Позиция латиноамериканских государств оказалась радикальнее российской: если Россия признала Национальный переходный совет Ливии, как и страны западного блока, то большинство латиноамериканских республик воздержалось от признания, а члены АЛБА отказались признавать этот временный орган власти, созданный противниками М.Каддафи.

\section{Сирийская проблема}

Сирийская проблема для международного сообщества стала серьезным испытанием: опыт Ливии показал, что силовое вмешательство только дестабилизирует регион и ведет к большей гуманитарной катастрофе. Развивающиеся государства стали более открыто и настойчиво осуждать любое вмешательство во внутренние дела. Бразилия настаивала на

решении проблемы политическим путем, «в рамках инклюзивного диалога и при поддержке международного сообщества» [12], чтобы Сирия «осталась территориально целостной, суверенной». Позиция Бразилия сводилась к тому, что «применение силовых мер приведет к катастрофическим последствиям в Сирии.

Большинство латиноамериканских республик выступило за мирное решение внутреннего конфликта в Сирии и против вмешательства во внутренние дела этой страны, что нашло отражение в заявлениях УНАСУР, АЛБА и СЕЛАК. Страны поддержали российскую инициативу по ликвидации химического оружия [13]. Резолюции Генеральной Ассамблеи $\mathrm{OOH}$ по ситуации в Сирии, осуждающие сирийские власти, трижды были не поддержаны 12 странами, в том числе Россией и 5 латиноамериканскими государствами-членами АЛБА (Венесуэла, Никарагуа, Боливия, Эквадор, Куба).

\section{События, в которые вовлечена Россия}

Конфликт между Россией и Грузией в 2008 году нашел живую реакцию в странах Латинской Америки. Свою поддержку высказала Венесуэла, которая в коммюнике объявила, что войну начала Грузия по указа- нию США. Россия по оценке Венесуэлы действовала в соответствии с международными соглашениями, регламентирующими нахождение её миротворцев в Южной Осетии, ради сохранения жизни населения, которое подвергалось «неприемлемым актам насилия со стороны грузинских войск». Аналогичную позицию заняла Куба, которая поддержала действия России на Кавказе. Два латиноамериканских государства Венесуэла и Никарагуа безоговорочно поддержали российскую политическую линию на Кавказе, признав Абхазию и Южную Осетию.

В 2014 году новый виток напряженных отношений России с западными странами был связан с решением Крымского вопроса и положением дел на территории ДНР и ЛНР. Латиноамериканские республики осудили политику двойных стандартов в отношении крымского вопроса. Голосование по резолюции 27 марта 2014 г., которая признавала референдум в Крыму не имеющим законной силы, показало, что регион менее зависим от влияния Запада и позиционирует себя в качестве самостоятельного актора: против проголосовали Никарагуа, Куба, Венесуэла и Боливия. Правом «молчаливого признания» воспользовались Бразилия, Аргентина, Эквадор, Уругвай и Парагвай[14]. Для Мексики, Коста-Рики и Панамы подходы по крымскому вопросу были продиктованы не американской линией, а историческим прошлым. Так, Панама осудила присоединение Крыма, поскольку ее территория - Панамский канал около ста лет находились под фактическим контролем США. Коста-Рика сохраняет территориальные споры с Никарагуа по поводу принадлежности несколько десятилетий назад возникшего безымянного острова на реке Сан-Хуан[15], однако в регионе существуют и другие территориальные конфликты, которые не стали доминировать во внешнеполитической позиции стран. МИД Мексики еще 4 марта 2014 г. выразил глубокую обеспокоенность событиями на Украине и в Автономной Республике Крым, подчеркнув необходимость соблюдения территориальной целостности Украины. Мексика имеет горький опыт потери территорий, когда в XIX веке США присоединили около половины мексиканской территории (современный штат Техас и штаты ЮгоЗапада). Мексика также призвала украинские власти гарантировать безопасность и права всех этнических групп, проживающих на территории Украины. Однако, несмотря на официальную позицию страны, $56 \%$ опрошенных в Мексике высказались в пользу уважения права жителей Крыма на самоопределение и присоединение к России, 57\% предположили, что на 


\section{Право и политика 6 (186) • 2015}

политику России не смогут повлиять введение США и Европой санкции [16].

Для России наиболее важной была позиция членов Группы двадцати - Аргентины, Бразилии и Мексики, которые в силу активной внешней политики могут воздействовать на формирование подходов других стран по этой проблеме. На аргентинские взгляды оказывают влияние такие факторы, как многолетний спор с Великобританией за суверенитет над Фолклендскими (Мальвинскими) островами, высокий уровень сотрудничества с Россией и многочисленность украинской общины с антироссийскими настроениями в стране. В силу первого фактора Аргентина проголосовала за непризнание результатов референдума в Крыму, опасаясь, что этот случай может быть использован как прецедент для Мальвинских островов, которые ранее на голосовании высказались за присоединение к Великобритании. Тогда же и российская позиция состояла в том, чтобы решить этот спор через аргентино-британские переговоры, игнорируя итоги выборов. Но после голосования президент страны К.Киршнер осудила Запад за признание референдума на Фолклендских островах и непризнание итогов крымского референдума. Позиция России по Фолклендским островам совпадает с Аргентинской: Россия регулярно поддерживает Аргентину в территориальном споре с Великобританией в Специальном комитете ООН по деколонизации. Бразилия заняла нейтральную позицию по Крымскому вопросу, несмотря на активную кампанию Запада по привлечению Бразилии в лагерь противников присоединения Крыма[17]. Хотя страна в данном вопросе исходила из приверженности принципу уважения невмешательства во внутренние дела, при достаточно «прохладном» отношении к принципу самоопределения народов и наций (в том числе из-за многочисленных проявлений сепаратизма южных штатов), состоявшийся саммит БРИКС в Форталезе в июле 2014 года продемонстрировал сохранение дружественных отношений между странами и готовность Бразилии расширять сотрудничество.

Куба, Венесуэла, Никарагуа и Боливия поддержали российскую позицию, сравнив ситуацию с аналогичными событиями в Ливии и Сирии. Хотя Эквадор воздержался при голосовании, президент Р. Корреа заявил, что считает нелегитимным правительство Украины.

Итак, резолюцию Генеральной Ассамблеи ООН А/ RES/68/262 о территориальной целостности Украины, которая подтверждает территориальную целостность страны и не признает изменение статуса Крыма, полностью поддержали члены Тихоокеанского союза, выступили против - государства объединения АЛБА и нейтральную позицию заняли члены МЕРКОСУР.

\section{Санкции как инструмент принуждения}

Латиноамериканский регион в целом негативно относится к любым санкциям, введенным в обход институциональных структур (органов ООН). Односторонние ограничительные меры, которые вводят США и Европа, не поддерживаются государствами. Так наиболее проблемным полем остаются санкции в отношении члена региона - Кубы. В 2009 году три государства - Гондурас, Никарагуа и Коста-Рика внесли в ОАГ резолюции, предусматривающие отмену санкций в отношении Кубы и восстановление членства в этой организации. Однако тогда Куба отказалась возвращаться в «империалистическую организацию», в знак солидарности президент Венесуэлы У.Чавес заявил о выходе из ОАГ. Позднее было объявлено об учреждении новой организации СЕЛАК без участия США. Таким образом, неприятие санкций регион выразил через переустройство на основе альтернативной системы регионального управления, обособление от США. Россия подтвердила незаконность блокады Кубы США в Декларации о принципах взаимоотношений между РФ и Кубой (1996 г.).

Показателен пример позиции Бразилии по санкциям против Ирана в 2008 году. Бразилия и Турция предложили альтернативу санкциям в виде взятого Ираном на себя обязательства отправлять уран для обогащения за границу. Однако достигнутое соглашение не вступило в силу, так как резолюцию о введении санкций поддержали КНР и Россия. Как непостоянные члены Совета Безопасности в тот момент Бразилия и Турция проголосовали против резолюции, однако их инициатива была отвергнута. В то же время Бразилия, которая считала санкции первым шагом на пути применения военной силы, как это было сделано в Ираке, стремилась стать доверенным листом в переговорах между США и Ираном [18].

Санкции против России не подержало ни одно из государств региона. Члены АЛБА высказали в целом единую позицию, что кризис на Украине был спровоцирован западными державами, которые действовали по сценарию, опробованному в Ливии и Сирии. В силу этого новое правительство на Украине признано ими нелегитимным и неспособным сохранить территориальную целостность страны. Страны региона не присоединились к санкциям, а напротив при введении российского продовольственного эмбарго предложили усилить торговое сотрудничество. 
Итак, анализ позиций стран по основным проблемам применения жесткой силы (hard power) показывает близость подходов России и латиноамериканских республик к решению ключевых международных проблем. По многим вопросам страны продемон- стрировали солидарность с российской позицией о недопустимости внешнего силового вмешательства, отмечается рост общей поддержки государствами региона российских международных инициатив, в первую очередь в рамках $\mathrm{OOH}$.

\section{Библиография:}

1. Давыдов В. М. и др. Латинская Америка в современной мировой политике. Российская акад. наук, Ин-т Латинской Америки. Москва, 2009

2. Жебит A.A. BRICS: перспектива глобального управления. // Латинская Америка, 2012, № 1.

3. Мартынов Б.Ф. Многополярный или многоцивилизационный мир?// Международные процессы. 2009. Т. 7. № 21. С. 13-131.

4. Scherer N. R. El bloque progresista y la Alianza del Pacífico// Miradas Al Sur, 29.09.2013

5. Мартынов Б. Ф.. Дилемма «многополярного мира» и Латинская Америка// Латинская Америка, № 10, 2009

6. Давыдов В. М. и др. Латинская Америка в современной мировой политике. Российская акад. наук, Ин-т Латинской Америки. Москва, 2009.

7. Проценко А. Е. Мексикано-американские отношения в условиях глобализации /дисс. канд. полит. наук, 23.00.04. М., Институт Латинской Америки, 2007

8. Declaracion de Lima para prevenir, combatir y eliminar el terrorismo// URL.: http://www.oas.org/juridico/spanish/terro2.htm

9. Аречага Э. Х. Современное международное право. М., 1983, с. 143.

10. Letter dated 9 November 2011 from the Permanent Representative of Brazil to the United Nations addressed to the SecretaryGeneral on 11 November 2011// Док.OOH A/66/551-S/2011/701(2011). URL: http://www.un.int/brazil/speech/Concept-Paper-\%20 RwP.pdf (дата обращения 12.02.2014)

11. South American countries divided over allied bombings of Libya // URL.: http://en.mercopress.com/2011/03/23/south-americancountries-divided-over-allied-bombings-of-libya

12. Выступление и ответы Министра иностранных дел России С.В.Лаврова на вопросы СМИ в ходе совместной прессконференции по итогам переговоров с Министром иностранных дел Бразилии А.Патриотой, Рио-де-Жанейро, 11 июня 2013 года // URL.: http://www.mid.ru/bdomp/foto.nsf/f7e05b65cc5781c0c3256d0100493e96/47af34e9664bfa9a44257b88001d6 66b!OpenDocument

13. Моисеев А. Актуальное интервью. Директор Латиноамериканского департамента МИД России Александр Щетинин: «Связи между Россией и Латинской Америкой динамичны и взаимовостребованы»// Международная жизнь, 7.10.2013

14. Филиппов Д. Перспективы «латиноамериканского ренессанса» во внешней политике России//РСМД, 22.04.2014

15. Сударев В. Россия и Латинская Америка на фоне украинского кризиса//Геополитика, 10.09.2014

16. El $72 \%$ de los mexicanos creen que su país no debe intervener en conflicto de Crimea. 03/31/2014// URL.: http://www. americaeconomia.com/

17. Яковлев П. Реакция в странах Латинской Америки на события в Крыму и вокруг Украины (в контексте российско-латиноамериканских отношений)// Геополитика, 28.05.2014

18. Дж. Свейг. Новый глобальный игрок: Масштабные планы Бразилии// Форин Афферс, 2010, № 6.

19. Сазонова К.Л. Международно-правовая ответственность международных организаций: проблемы и перспективы // Международное право. - 2012. - 1. - С. 16 - 25. URL: http://www.e-notabene.ru/wl/article_371.html

20. Осипян Б.А. Правовые основы международной безопасности // Международное право и международные организации / International Law and International Organizations. - 2014. - 2. - C. 245 - 254. DOI: 10.7256/2226-6305.2014.2.12111.

21. О.Г. Карпович Антиглобализм и современные концепции глобального управления // Политика и Общество. - 2013. - 3. - C. 305 - 314. DOI: 10.7256/1812-8696.2013.03.6.

\section{References (transliterated):}

1. Davydov V. M. i dr. Latinskaya Amerika v sovremennoi mirovoi politike. Rossiiskaya akad. nauk, In-t Latinskoi Ameriki. Moskva, 2009

2. Zhebit A.A. BRICS: perspektiva global'nogo upravleniya. // Latinskaya Amerika, 2012, № 1 .

3. Martynov B.F. Mnogopolyarnyi ili mnogotsivilizatsionnyi mir?// Mezhdunarodnye protsessy. 2009. T. 7. № 21. S. $13-131$.

4. Scherer N. R. El bloque progresista y la Alianza del Pacífico// Miradas Al Sur, 29.09.2013

5. Martynov B. F.. Dilemma «mnogopolyarnogo mira» i Latinskaya Amerika// Latinskaya Amerika, № 10, 2009

6. Davydov V. M. i dr. Latinskaya Amerika v sovremennoi mirovoi politike. Rossiiskaya akad. nauk, In-t Latinskoi Ameriki. Moskva, 2009.

7. Protsenko A. E. Meksikano-amerikanskie otnosheniya v usloviyakh globalizatsii /diss. kand. polit. nauk, 23.00.04. M., Institut Latinskoi Ameriki, 2007

8. Arechaga E. Kh. Sovremennoe mezhdunarodnoe pravo. M., 1983, s. 143. 
DOI: $10.7256 / 1811-9018.2015 .6 .14698$

При цитировании этой статьи сноска на доі обязательна

\section{Право и политика $6(186) \cdot 2015$}

9. Moiseev A. Aktual'noe interv’yu. Direktor Latinoamerikanskogo departamenta MID Rossii Aleksandr Shchetinin: «Svyazi mezhdu Rossiei i Latinskoi Amerikoi dinamichny i vzaimovostrebovany»// Mezhdunarodnaya zhizn', 7.10.2013

10. Filippov D. Perspektivy «latinoamerikanskogo renessansa» vo vneshnei politike Rossii//RSMD, 22.04.2014

11. Sudarev V. Rossiya i Latinskaya Amerika na fone ukrainskogo krizisa//Geopolitika, 10.09.2014

12. Yakovlev P. Reaktsiya v stranakh Latinskoi Ameriki na sobytiya v Krymu i vokrug Ukrainy (v kontekste rossiisko-latinoamerikanskikh otnoshenii)// Geopolitika, 28.05.2014

13. Dzh. Sveig. Novyi global'nyi igrok: Masshtabnye plany Brazilii// Forin Affers, 2010, № 6.

14. Sazonova K.L. Mezhdunarodno-pravovaya otvetstvennost' mezhdunarodnykh organizatsii: problemy i perspektivy // Mezhdunarodnoe pravo. - 2012. - 1. - C. 16 - 25. URL: http://www.e-notabene.ru/wl/article_371.html

15. Osipyan B.A. Pravovye osnovy mezhdunarodnoi bezopasnosti // Mezhdunarodnoe pravo i mezhdunarodnye organizatsii / International Law and International Organizations. - 2014. - 2. - C. 245 - 254. DOI: 10.7256/2226-6305.2014.2.12111.

16. O.G. Karpovich Antiglobalizm i sovremennye kontseptsii global'nogo upravleniya // Politika i Obshchestvo. - 2013 . - 3. - C. 305 - 314. DOI: 10.7256/1812-8696.2013.03.6. 